\title{
A Literature Review: Website Design and User Engagement
}

\author{
Renee Garett, UCLA, USA \\ Jason Chiu, UCLA, USA \\ Ly Zhang, UCLA, USA \\ Sean D. Young, UCLA, USA
}

\begin{abstract}
Proper design has become a critical element needed to engage website and mobile application users. However, little research has been conducted to define the specific elements used in effective website and mobile application design. We attempt to review and consolidate research on effective design and to define a short list of elements frequently used in research. The design elements mentioned most frequently in the reviewed literature were navigation, graphical representation, organization, content utility, purpose, simplicity, and readability. We discuss how previous studies define and evaluate these seven elements. This review and the resulting short list of design elements may be used to help designers and researchers to operationalize best practices for facilitating and predicting user engagement.
\end{abstract}

Keywords: Website design, usability, navigation, organization, simplicity 


\section{Introduction}

Internet usage has increased tremendously and rapidly in the past decade ("Internet Use Over Time,” 2014). Websites have become the most important public communication portal for most, if not all, businesses and organizations. As of 2014, 87\% of American adults aged 18 or older are Internet users (“Internet User Demographics,” 2013). Because business-toconsumer interactions mainly occur online, website design is critical in engaging users (Flavián, Guinalíu, \& Gurrea, 2006; Lee \& Kozar, 2012; Petre, Minocha, \& Roberts, 2006). Poorly designed websites may frustrate users and result in a high "bounce rate", or people visiting the entrance page without exploring other pages within the site (Google.com, 2015). On the other hand, a well-designed website with high usability has been found to positively influence visitor retention (revisit rates) and purchasing behavior (Avouris, Tselios, Fidas, \& Papachristos, 2003; Flavián et al., 2006; Lee \& Kozar, 2012).

Little research, however, has been conducted to define the specific elements that constitute effective website design. One of the key design measures is usability (International Standardization Organization, 1998). The International Standardized Organization (ISO) defines usability as the extent to which users can achieve desired tasks (e.g., access desired information or place a purchase) with effectiveness (completeness and accuracy of the task), efficiency (time spent on the task), and satisfaction (user experience) within a system. However, there is currently no consensus on how to properly operationalize and assess website usability (Lee \& Kozar, 2012). For example, Nielson associates usability with learnability, efficiency, memorability, errors, and satisfaction (Nielsen, 2012). Yet, Palmer (2002) postulates that usability is determined by download time, navigation, content, interactivity, and responsiveness. Similar to usability, many other key design elements, such as scannability, readability, and visual aesthetics, have not yet been clearly defined (Bevan, 1997; Brady \& Phillips, 2003; Kim, Lee, Han, \& Lee, 2002), and there are no clear guidelines that individuals can follow when designing websites to increase engagement.

This review sought to address that question by identifying and consolidating the key website design elements that influence user engagement according to prior research studies. This review aimed to determine the website design elements that are most commonly shown or suggested to increase user engagement. Based on these findings, we listed and defined a short list of website design elements that best facilitate and predict user engagement. The work is 
thus an exploratory research providing definitions for these elements of website design and a starting point for future research to reference.

\section{Materials and Methods}

\section{Selection Criteria and Data Extraction}

We searched for articles relating to website design on Google Scholar (scholar.google.com) because Google Scholar consolidates papers across research databases (e.g., Pubmed) and research on design is listed in multiple databases. We used the following combination of keywords: design, usability, and websites. Google Scholar yielded 115,000 total hits. However, due to the large list of studies generated, we decided to only review the top 100 listed research studies for this exploratory study.

Our inclusion criteria for the studies was: (1) publication in a peer-reviewed academic journal, (2) publication in English, and (3) publication in or after 2000. Year of publication was chosen as a limiting factor so that we would have enough years of research to identify relevant studies but also have results that relate to similar styles of websites after the year 2000. We included studies that were experimental or theoretical (review papers and commentaries) in nature. Resulting studies represented a diverse range of disciplines, including human-computer interaction, marketing, e-commerce, interface design, cognitive science, and library science. Based on these selection criteria, thirty-five unique studies remained and were included in this review.

\section{Final Search Term}

\section{(design) AND (usability) AND (websites)}

The search terms were kept simple to capture the higher level design/usability papers and allow Google scholar's ranking method to filter out the most popular studies. This method also allowed studies from a large range of fields to be searched.

\section{Analysis}

The literature review uncovered 20 distinct design elements commonly discussed in research that affect user engagement. They were (1) organization - is the website logically organized, (2) content utility - is the information provided useful or interesting, (3) navigation - is the website easy to navigate, (4) graphical representation - does the website utilize icons, 
contrasting colors, and multimedia content, (5) purpose - does the website clearly state its purpose (i.e. personal, commercial, or educational), (6) memorable elements - does the website facilitate returning users to navigate the site effectively (e.g., through layout or graphics), (7) valid links - does the website provide valid links, (8) simplicity - is the design of the website simple, (9) impartiality - is the information provided fair and objective, (10) credibility - is the information provided credible, (11) consistency/reliability - is the website consistently designed (i.e., no changes in page layout throughout the site), (12) accuracy - is the information accurate, (13) loading speed - does the website take a long time to load, (14) security/privacy - does the website securely transmit, store, and display personal information/data, (15) interactive - can the user interact with the website (e.g., post comments or receive recommendations for similar purchases), (16) strong user control capabilities- does the website allow individuals to customize their experiences (such as the order of information they access and speed at which they browse the website), (17) readability - is the website easy to read and understand (e.g., no grammatical/spelling errors), (18) efficiency - is the information presented in a way that users can find the information they need quickly, (19) scannability - can users pick out relevant information quickly, and (20) learnability - how steep is the learning curve for using the website. For each of the above, we calculated the proportion of studies mentioning the element. In this review, we provide a threshold value of $30 \%$. We identified elements that were used in at least $30 \%$ of the studies and include these elements that are above the threshold on a short list of elements used in research on proper website design. The $30 \%$ value was an arbitrary threshold picked that would provide researchers and designers with a guideline list of elements described in research on effective web design. To provide further information on how to apply this list, we present specific details on how each of these elements was discussed in research so that it can be defined and operationalized.

\section{Results}

\section{Popular Website Design Elements (Table 1)}

Seven of the website design elements met our threshold requirement for review. Navigation was the most frequently discussed element, mentioned in 22 articles (62.86\%). Twenty-one studies (60\%) highlighted the importance of graphics. Fifteen studies (42.86\%) emphasized good organization. Four other elements also exceeded the threshold level, and they were 
content utility ( $n=13,37.14 \%)$, purpose $(n=11,31.43 \%)$, simplicity ( $n=11,31.43 \%)$, and readability $(\mathrm{n}=11,31.43 \%)$.

Elements below our minimum requirement for review include memorable features $(n=5$, 14.29\%), links ( $n=10,28.57 \%)$, impartiality $(n=1,2.86 \%)$, credibility $(n=7,20 \%)$, consistency/reliability ( $\mathrm{n}=8.22 .86 \%)$, accuracy $(\mathrm{n}=5,14.29 \%)$, loading speed $(\mathrm{n}=10$, 28.57\%), security/privacy ( $n=2,5.71 \%)$, interactive features $(n=9,25.71 \%)$, strong user control capabilities ( $n=8,22.86 \%)$, efficiency $(n=6,17.14 \%)$, scannability $(n=1,2.86 \%)$, and learnability ( $\mathrm{n}=2,5.71 \%)$.

Table 1 - Frequency of website design elements used in research (2000-2014)

\begin{tabular}{|c|c|c|c|c|c|c|c|}
\hline & & Elements* & & & & & \\
\hline Authors & Year & Organization & $\begin{array}{l}\text { Content } \\
\text { Utility }\end{array}$ & Navigation & $\begin{array}{l}\text { Graphical } \\
\text { Representation }\end{array}$ & Purpose & Simplicity \\
\hline Rosen \& Purinton & 2004 & 1 & 1 & 1 & 1 & 1 & 1 \\
\hline Tan \& Wei & 2007 & 1 & & 1 & 1 & 1 & 1 \\
\hline Cyr, Head, \& Larios & 2010 & & & & 1 & & \\
\hline $\begin{array}{l}\text { Arroyo, Selker, \& } \\
\text { Wei }\end{array}$ & 2006 & 1 & & 1 & & & 1 \\
\hline Tarafdar \& Zhang & 2008 & 1 & 1 & 1 & & & \\
\hline Flavián et al. & 2006 & & & 1 & & & \\
\hline George & 2005 & 1 & & 1 & 1 & & 1 \\
\hline Zhang \& Von Dran & 2000 & & 1 & & 1 & 1 & \\
\hline $\begin{array}{l}\text { Thompson, Braddy, } \\
\text { \& Wuensch }\end{array}$ & 2008 & 1 & & 1 & 1 & 1 & \\
\hline $\begin{array}{l}\text { Williamson, Lepak, } \\
\text { \& King }\end{array}$ & 2003 & & & 1 & & 1 & \\
\hline Maurer \& Liu & 2007 & & 1 & & 1 & 1 & \\
\hline $\begin{array}{l}\text { Braddy, Meade, \& } \\
\text { Kroustalis }\end{array}$ & 2008 & & & & 1 & & \\
\hline $\begin{array}{l}\text { Atterer, Wnuk, \& } \\
\text { Schmidt }\end{array}$ & 2006 & & & 1 & & & 1 \\
\hline $\begin{array}{l}\text { Belanche, Casaló, \& } \\
\text { Guinalíu }\end{array}$ & 2012 & 1 & & 1 & 1 & 1 & 1 \\
\hline Djonov & 2007 & 1 & & 1 & & 1 & \\
\hline Lee \& Kozar & 2012 & & & 1 & & & 1 \\
\hline Dastidar & 2009 & 1 & 1 & 1 & & 1 & \\
\hline Sutcliffe & 2001 & 1 & 1 & 1 & 1 & 1 & 1 \\
\hline $\begin{array}{l}\text { Cyr, Ilsever, } \\
\text { Bonanni, \& Bowes }\end{array}$ & 2004 & 1 & & 1 & 1 & 1 & \\
\hline $\begin{array}{l}\text { Blackmon, Polson, } \\
\text { Kitajima, \& Lewis }\end{array}$ & 2002 & 1 & & & 1 & 1 & \\
\hline
\end{tabular}




\begin{tabular}{|c|c|c|c|c|c|c|c|}
\hline $\begin{array}{lll}\text { Banati, } & \text { Bedi, } \quad \& \\
\text { Grover } & \end{array}$ & 2006 & & 1 & & & & \\
\hline $\begin{array}{l}\text { Djamasbi, Siegel, \& } \\
\text { Tullis }\end{array}$ & 2010 & & & 1 & 1 & & \\
\hline Raward & 2001 & & & 1 & 1 & & 1 \\
\hline $\begin{array}{l}\text { De Angeli, Sutcliffe, } \\
\text { \& Hartmann }\end{array}$ & 2006 & & 1 & 1 & 1 & & \\
\hline $\begin{array}{l}\text { Blackmon, Kitajima, } \\
\text { \& Polson }\end{array}$ & 2003 & & & & & & \\
\hline Song \& Zahedi & 2005 & & 1 & 1 & 1 & & \\
\hline Lowry et al & 2006 & & & & & & \\
\hline Avouris et al & 2003 & & 1 & & 1 & & \\
\hline Auger & 2005 & & & & 1 & & 1 \\
\hline Green \& Pearson & 2006 & & 1 & & & & \\
\hline $\begin{array}{l}\text { Zhang, Small, Von } \\
\text { Dran, \& Barcellos }\end{array}$ & 2000 & & 1 & & & & \\
\hline $\begin{array}{l}\text { Shneiderman \& } \\
\text { Hochheiser }\end{array}$ & 2001 & & & & & & \\
\hline $\begin{array}{l}\text { Petrie, Hamilton, \& } \\
\text { King }\end{array}$ & 2004 & 1 & & 1 & 1 & 1 & 1 \\
\hline Petre et al & 2006 & 1 & 1 & 1 & 1 & 1 & \\
\hline Lim & 2002 & 1 & & 1 & 1 & 1 & \\
\hline Total & & 15 & 13 & 22 & 21 & 11 & 11 \\
\hline$\%$ & & 42.86 & 37.14 & 62.86 & 60 & 31.43 & 31.43 \\
\hline Ranking & & 3 & 4 & 1 & 2 & 5 & 5 \\
\hline
\end{tabular}

* Elements in table all met the 30\%+ threshold; elements not meeting the 30\% threshold are not shown.

\section{Defining Key Design Elements for User Engagement (Table 2)}

In defining and operationalizing each of these elements, the research studies suggested that effective navigation is the presence of salient and consistent menu/navigation bars, aids for navigation (e.g., visible links), search features, and easy access to pages (multiple pathways and limited clicks/backtracking). Engaging graphical presentation entails 1) inclusion of images, 2) proper size and resolution of images, 3) multimedia content, 4) proper color, font, and size of text, 5) use of logos and icons, 6) attractive visual layout, 7) color schemes, and 8) effective use of white space. Optimal organization includes 1) cognitive architecture, 2) logical, understandable, and hierarchical structure, 3) information arrangement and categorization, 4) meaningful labels/headings/titles, and 5) use of keywords. Content utility is determined by 1) sufficient amount of information to attract repeat visitors, 2) arousal/motivation (keeps visitors interested and motivates users to continue exploring the 
site), 3) content quality, 4) information relevant to the purpose of the site, and 5) perceived utility based on user needs/requirements. The purpose of a website is clear when it 1) establishes a unique and visible brand/identity, 2) addresses visitors' intended purpose and expectations for visiting the site, and 3) provides information about the organization and/or services. Simplicity is achieved by using 1) simple subject headings, 2) transparency of information (reduce search time), 3) website design optimized for computer screens, 4) uncluttered layout, 5) consistency in design throughout website, 6) ease of using (including first-time users), 7) minimize redundant features, and 8) easily understandable functions. Readability is optimized by content that is 1) easy to read, 2) well-written, 3) grammatically correct, 4) understandable, 5) presented in readable blocks, and 6) reading level appropriate.

Table 2 - Definitions of Key Design Elements

\begin{tabular}{|c|c|}
\hline Key Elements & Definition \\
\hline Navigation & $\begin{array}{l}\text { - } \text { Salient menu/navigation bar } \\
\text { - } \text { Consistency of navigation bar } \\
\text { - } \text { Aids for navigation (e.g., visible links) } \\
\text { - } \text { Easy access to web pages (e.g., no excessive } \\
\text { backtracking/clicks and reach through multiple pathways) } \\
\text { - Search features } \\
\text { - Users feel in control/ease of managing }\end{array}$ \\
\hline $\begin{array}{l}\text { Graphical } \\
\text { Representation }\end{array}$ & $\begin{array}{ll}\text { - } & \text { Inclusion of images } \\
\text { - } & \text { Size and resolution of images } \\
\text { - } & \text { Multimedia content (e.g., animation or audio) } \\
\text { - } & \text { Color, font, and size of text } \\
\text { - } & \text { Distinct logos and icons } \\
\text { - } & \text { Visual attractiveness/layout } \\
\text { - } & \text { Color schemes } \\
\text { - } & \text { Effective use of white space/avoid visual overload } \\
\text { - } & \text { Minimizing loading time for visual elements }\end{array}$ \\
\hline Organization & $\begin{array}{ll}\text { - } & \text { Cognitive mapping/architecture } \\
\text { - } & \text { Understandable structure } \\
\text { - } & \text { Logical organization }\end{array}$ \\
\hline
\end{tabular}




\begin{tabular}{|c|c|}
\hline & $\begin{array}{l}\text { - Hierarchical/sequencing organization } \\
\text { - Systematic information arrangement and categorization } \\
\text { - Consistency } \\
\text { - Meaningful labels/headings/titles } \\
\text { - Keywords }\end{array}$ \\
\hline $\begin{array}{l}\text { Content } \\
\text { Utility }\end{array}$ & 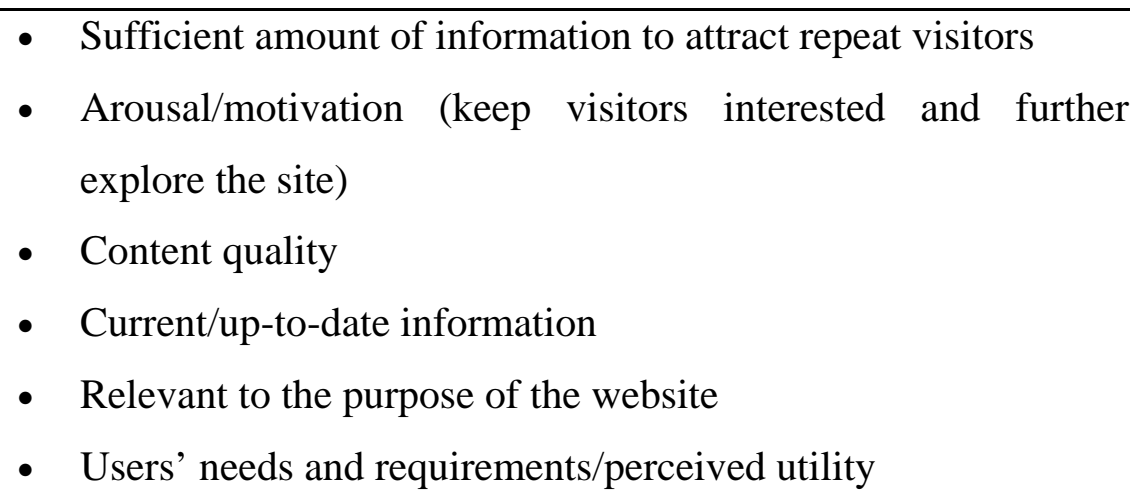 \\
\hline Purpose & $\begin{array}{l}\text { - } \text { Unique identity } \\
\text { - } \text { Intended purpose of visiting/expectations } \\
\text { - } \text { Type of interaction } \\
\text { - } \text { Organizational attractiveness } \\
\text { - Visible brand/contact and organization information } \\
\text { - Information about service policy }\end{array}$ \\
\hline Simplicity & $\begin{array}{l}\text { - } \text { - Timple subject headings } \\
\text { - } \text { Website design optimized for computer screens } \\
\text { - Uncluttered layout } \\
\text { - Consistency in design throughout the website } \\
\text { - Ease of using (including first time users) } \\
\text { - } \text { Minimize redundant features } \\
\text { - Easily understandable features/functions }\end{array}$ \\
\hline Readability & $\begin{array}{ll}\text { - } & \text { Easy to read } \\
\text { - Well-written } \\
\text { - Grammatically correct } \\
\text { - } \\
\text { - } \\
\text { - } \\
\text { - } \\
\text { Reading levstandable } \\
\end{array}$ \\
\hline
\end{tabular}




\section{Discussion}

The seven website design elements most often discussed in relation to user engagement in the reviewed studies were navigation (62.86\%), graphical representation (60\%), organization (42.86\%), content utility (37.14\%), purpose (31.43\%), simplicity (31.43\%), and readability (31.43\%). These seven elements exceeded our threshold level of 30\% representation in the literature and were included into a short list of website design elements to operationalize effective website design. For further analysis, we reviewed how studies defined and evaluated these seven elements. This may allow designers and researchers to determine and follow best practices for facilitating or predicting user engagement.

A remaining challenge is that the definitions of website design elements often overlap. For example, several studies evaluated organization by how well a website incorporates cognitive architecture, logical and hierarchical structure, systematic information arrangement and categorization, meaningful headings and labels, and keywords. However, these features are also crucial in navigation design. Also, the implications of using distinct logos and icons go beyond graphical representation. Logos and icons also establish unique brand/identity for the organization (purpose) and can serve as visual aids for navigation. Future studies are needed to develop distinct and objective measures to assess these elements and how they affect user engagement (Lee \& Kozar, 2012).

Given the rapid increase in both mobile technology and social media use, it is surprising that no studies mentioned cross-platform compatibility and social media integration. In 2013, $34 \%$ of cellphone owners primarily use their cellphones to access the Internet, and this number continues to grow ("Mobile Technology Factsheet," 2013). With the rise of different mobile devices, users are also diversifying their web browser use. Internet Explorer (IE) was once the leading web browser. However, in recent years, FireFox, Safari, and Chrome have gained significant traction (W3schools.com, 2015). Website designers and researchers must be mindful of different platforms and browsers to minimize the risk of losing users due to compatibility issues. In addition, roughly $74 \%$ of American Internet users use some form of social media (Duggan, Ellison, Lampe, Lenhart, \& Smith, 2015), and social media has emerged as an effective platform for organizations to target and interact with users. Integrating social media into website design may increase user engagement by facilitating participation and interactivity. 
There are several limitations to the current review. First, due to the large number of studies published in this area and due to this study being exploratory, we selected from the first 100 research publications on Google Scholar search results. Future studies may benefit from defining design to a specific topic, set of years, or other area to limit the number of search results. Second, we did not quantitatively evaluate the effectiveness of these website design elements. Additional research can help to better quantify these elements.

It should also be noted that different disciplines and industries have different objectives in designing websites and should thus prioritize different website design elements. For example, online businesses and marketers seek to design websites that optimize brand loyalty, purchase, and profit (Petre et al., 2006). Others, such as academic researchers or healthcare providers, are more likely to prioritize privacy/confidentiality, and content accuracy in building websites (Horvath, Ecklund, Hunt, Nelson, \& Toomey, 2015). Ultimately, we advise website designers and researchers to consider the design elements delineated in this review, along with their unique needs, when developing user engagement strategies. 


\section{References}

Arroyo, Ernesto, Selker, Ted, \& Wei, Willy. (2006). Usability tool for analysis of web designs using mouse tracks. Paper presented at the CHI'06 Extended Abstracts on Human Factors in Computing Systems.

Atterer, Richard, Wnuk, Monika, \& Schmidt, Albrecht. (2006). Knowing the user's every move: user activity tracking for website usability evaluation and implicit interaction. Paper presented at the Proceedings of the 15th international conference on World Wide Web.

Auger, Pat. (2005). The impact of interactivity and design sophistication on the performance of commercial websites for small businesses. Journal of Small Business Management, 43(2), 119-137.

Avouris, Nikolaos, Tselios, Nikolaos, Fidas, Christos, \& Papachristos, Eleftherios. (2003). Website evaluation: A usability-based perspective Advances in Informatics (pp. 217231): Springer.

Banati, Hema, Bedi, Punam, \& Grover, PS. (2006). Evaluating web usability from the user's perspective. Journal of Computer Science, 2(4), 314.

Belanche, Daniel, Casaló, Luis V, \& Guinalíu, Miguel. (2012). Website usability, consumer satisfaction and the intention to use a website: The moderating effect of perceived risk. Journal of retailing and consumer services, 19(1), 124-132.

Bevan, Nigel. (1997). Usability issues in web site design. Paper presented at the HCI (2).

Blackmon, Marilyn Hughes, Kitajima, Muneo, \& Polson, Peter G. (2003). Repairing usability problems identified by the cognitive walkthrough for the web. Paper presented at the Proceedings of the SIGCHI conference on Human factors in computing systems.

Blackmon, Marilyn Hughes, Polson, Peter G, Kitajima, Muneo, \& Lewis, Clayton. (2002). Cognitive walkthrough for the web. Paper presented at the Proceedings of the SIGCHI conference on human factors in computing systems.

Braddy, Phillip W, Meade, Adam W, \& Kroustalis, Christina M. (2008). Online recruiting: The effects of organizational familiarity, website usability, and website attractiveness on viewers' impressions of organizations. Computers in Human Behavior, 24(6), 2992-3001.

Brady, Laurie, \& Phillips, Christine. (2003). Aesthetics and usability: A look at color and balance. Usability News, 5(1), 2003. 
Cyr, Dianne, Head, Milena, \& Larios, Hector. (2010). Colour appeal in website design within and across cultures: A multi-method evaluation. International journal of humancomputer studies, 68(1), 1-21.

Cyr, Dianne, Ilsever, Joe, Bonanni, Carole, \& Bowes, John. (2004). Website Design and Culture: An Empirical Investigation. Paper presented at the IWIPS.

Dastidar, Surajit Ghosh. (2009). Impact of the factors influencing website usability on user satisfaction.

De Angeli, Antonella, Sutcliffe, Alistair, \& Hartmann, Jan. (2006). Interaction, usability and aesthetics: what influences users' preferences? Paper presented at the Proceedings of the 6th conference on Designing Interactive systems.

Djamasbi, Soussan, Siegel, Marisa, \& Tullis, Tom. (2010). Generation Y, web design, and eye tracking. International journal of human-computer studies, 68(5), 307-323.

Djonov, Emilia. (2007). Website hierarchy and the interaction between content organization, webpage and navigation design: A systemic functional hypermedia discourse analysis perspective. Information Design Journal, 15(2), 144-162.

Duggan, M., Ellison, N., Lampe, C., Lenhart, A., \& Smith, A. (2015). Social Media update 2014. Washington, D.C.: Pew Research Center.

Flavián, Carlos, Guinalíu, Miguel, \& Gurrea, Raquel. (2006). The role played by perceived usability, satisfaction and consumer trust on website loyalty. Information \& Management, 43(1), 1-14.

George, Carole A. (2005). Usability testing and design of a library website: an iterative approach. OCLC Systems \& Services: International digital library perspectives, 21(3), 167-180.

Google.com. (2015). Bounce Rate. Analyrics Help. Retrieved 2/11, 2015, from https://support.google.com/analytics/answer/1009409?hl=en

Green, D., \& Pearson, J.M. (2006). Development of a web site usability instrument based on ISO 9241-11. Journal of Computer Information Systems, Fall.

Horvath, Keith J, Ecklund, Alexandra M, Hunt, Shanda L, Nelson, Toben F, \& Toomey, Traci L. (2015). Developing Internet-Based Health Interventions: A Guide for Public Health Researchers and Practitioners. J Med Internet Res, 17(1), e28. doi: 10.2196/jmir.3770 
International Standardization Organization. (1998). ISO 2941-11:1998 Ergonomic requirements for office work with visual display terminals (VDTs) -- Part 11: Guidance on usability: International Standardization Organization (ISO). Internet Use Over Time. (2014, January 2). Retrieved February 15, 2015, from http://www.pewinternet.org/data-trend/internet-use/internet-use-over-time/ Internet User Demographics. (2013, November 14). Retrieved February 11, 2015, from http://www.pewinternet.org/data-trend/internet-use/latest-stats/

Kim, Jinwoo, Lee, Jungwon, Han, Kwanghee, \& Lee, Moonkyu. (2002). Businesses as Buildings: Metrics for the Architectural Quality of Internet Businesses. Information Systems Research, 13(3), 239-254. doi: doi:10.1287/isre.13.3.239.79

Lee, Younghwa, \& Kozar, Kenneth A. (2012). Understanding of website usability: Specifying and measuring constructs and their relationships. Decision Support Systems, 52(2), 450-463.

Lim, Sun. (2002). The Self-Confrontation Interview: Towards an Enhanced Understanding of Human Factors in Web-based Interaction for Improved Website Usability. $J$. Electron. Commerce Res., 3(3), 162-173.

Lowry, Paul Benjamin, Spaulding, Trent, Wells, Taylor, Moody, Greg, Moffit, Kevin, \& Madariaga, Sebastian. (2006). A theoretical model and empirical results linking website interactivity and usability satisfaction. Paper presented at the System Sciences, 2006. HICSS'06. Proceedings of the 39th Annual Hawaii International Conference on.

Maurer, Steven D, \& Liu, Yuping. (2007). Developing effective e-recruiting websites: Insights for managers from marketers. Business Horizons, 50(4), 305-314.

Mobile Technology Fact Sheet. (2013, December 27). Retrieved August 5, 2015, from http://www.pewinternet.org/fact-sheets/mobile-technology-fact-sheet/

Nielsen, Jakob. (2012). Usability 101: introduction to Usability. Retrieved 2/11, 2015, from http://www.nngroup.com/articles/usability-101-introduction-to-usability/

Palmer, Jonathan W. (2002). Web Site Usability, Design, and Performance Metrics. Information Systems Research, 13(2), 151-167. doi: doi:10.1287/isre.13.2.151.88

Petre, Marian, Minocha, Shailey, \& Roberts, Dave. (2006). Usability beyond the website: an empirically-grounded e-commerce evaluation instrument for the total customer experience. Behaviour \& Information Technology, 25(2), 189-203. 
Petrie, Helen, Hamilton, Fraser, \& King, Neil. (2004). Tension, what tension?: Website accessibility and visual design. Paper presented at the Proceedings of the 2004 international cross-disciplinary workshop on Web accessibility (W4A).

Raward, Roslyn. (2001). Academic library website design principles: development of a checklist. Australian Academic \& Research Libraries, 32(2), 123-136.

Rosen, Deborah E, \& Purinton, Elizabeth. (2004). Website design: Viewing the web as a cognitive landscape. Journal of Business Research, 57(7), 787-794.

Shneiderman, Ben, \& Hochheiser, Harry. (2001). Universal usability as a stimulus to advanced interface design. Behaviour \& Information Technology, 20(5), 367-376.

Song, Jaeki, \& Zahedi, Fatemeh "Mariam”. (2005). A theoretical approach to web design in e-commerce: a belief reinforcement model. Management Science, 51(8), 1219-1235.

Sutcliffe, Alistair. (2001). Heuristic evaluation of website attractiveness and usability Interactive systems: design, specification, and verification (pp. 183-198): Springer.

Tan, Gek Woo, \& Wei, Kwok Kee. (2007). An empirical study of Web browsing behaviour: Towards an effective Website design. Electronic Commerce Research and Applications, 5(4), 261-271.

Tarafdar, Monideepa, \& Zhang, Jie. (2008). Determinants of reach and loyalty-a study of Website performance and implications for Website design. Journal of Computer Information Systems, 48(2), 16.

Thompson, Lori Foster, Braddy, Phillip W, \& Wuensch, Karl L. (2008). E-recruitment and the benefits of organizational web appeal. Computers in Human Behavior, 24(5), 2384-2398.

W3schools.com.). Browser Statistics and Trends. Retrieved 1/15, 2015, from http://www.w3schools.com/browsers/browsers_stats.asp

Williamson, Ian O, Lepak, David P, \& King, James. (2003). The effect of company recruitment web site orientation on individuals' perceptions of organizational attractiveness. Journal of Vocational Behavior, 63(2), 242-263.

Zhang, Ping, Small, Ruth V, Von Dran, Gisela M, \& Barcellos, Silvia. (2000). A two factor theory for website design. Paper presented at the System Sciences, 2000. Proceedings of the 33rd Annual Hawaii International Conference on.

Zhang, Ping, \& Von Dran, Gisela M. (2000). Satisfiers and dissatisfiers: A two-factor model for website design and evaluation. Journal of the American society for information science, 51(14), 1253-1268. 